\title{
Pengaruh Timur Tengah Terhadap Madrasah Al-Mashoor Al-Islamiah
}

\author{
Ahmad Dzulfahmi Muhamada,b* \\ ${ }^{a}$ Fakulti Tamadun Islam, Universiti Teknologi Malaysia, 81310 UTM Johor Bahru, Johor Darul Takzim, \\ ${ }^{b}$ Pusat Pengajian Pendidikan Jarak Jauh, Universiti Sains Malaysia, 11800 USM Pulau Pinang.
}

*Corresponding author: adzul74@gmail.com

\begin{abstract}
Middle Eastern influences play an important role in the Madrasah al-Mashoor al-Islamiah in Penang Islamic education system and is a major factor madrasah education system is growing rapidly. Effect of the Middle East, especially from Egypt and Makkah in the development of Islamic education in Malaya who have contributed to the realization of the Malay Muslim sociopolitical effects of the Islah movement in the Middle East in the field of education. This rapid development is due to the role taken by Syed Sheikh al-Hadi in bringing reforms in the education system, curriculum, teaching staff and in terms of magazine publishing. The main method in this study is the use of qualitative research methods based on primary and secondary sources. Primary sources such as private letters, books, souvenirs Madrasah al-Mashoor and resources in analyzing this approach to history. Secondary sources were used such as articles, journals, books, newspapers and theses. The study found that the influence of the Middle East proved to be one factor in the rapid development and the role of education in Madrasah al-Islam al-Islamiah Mashoor. This effect has also caused Madrasah al-Mashoor al-Islamiah become famous and be a focal point for students in the Malay Archipelago for their studies.
\end{abstract}

Keywords: Islamic education; madrasah; middle east influence

\begin{abstract}
Abstrak
Pengaruh Timur Tengah memainkan peranan penting terhadap Madrasah al-Mashoor al-Islamiah Pulau Pinang dalam bidang sistem Pendidikan Islam dan merupakan faktor utama sistem pengajian madrasah ini berkembang pesat. Pengaruh dari Timur Tengah khususnya dari Mesir dan Makkah dalam perkembangan Pendidikan Islam di Tanah Melayu yang telah menyumbang kepada kesedaran sosiopolitik masyarakat Melayu Islam kesan daripada pengaruh gerakan Islah di Timur Tengah dalam bidang pendidikan. Perkembangan pesat ini disebabkan oleh peranan yang dibawa oleh Syed Syeikh al-Hadi dalam membawa pembaharuan dalam sistem pengajian, kurikulum, tenaga pengajar serta dalam aspek penerbitan majalah. Kaedah utama dalam kajian ini adalah menggunakan kaedah penyelidikan kualitatif berdasarkan sumber primer dan sekunder. Sumber primer seperti surat persendirian, buku cenderamata Madrasah al-Mashoor dan sumber ini di analisa menggunakan pendekatan sejarah. Sumber sekunder yang digunakan adalah seperti artikel, jurnal, buku, akhbar dan tesis. Hasil kajian mendapati pengaruh Timur Tengah terbukti menjadi salah satu faktor perkembangan pesat dan berperanan dalam aspek pendidikan Islam di Madrasah al-Mashoor al-Islamiah. Pengaruh ini juga telah menyebabkan Madrasah al-Mashoor al-Islamiah menjadi terkenal dan menjadi tumpuan pelajar di Kepulauan Melayu untuk menyambung pelajaran mereka.
\end{abstract}

Kata Kunci: Pendidikan islam; madrasah; pengaruh timur tengah

(C) 2016 Penerbit UTM Press. All rights reserved

\subsection{PENGENALAN}

Perkembangan madrasah di Tanah Melayu semakin pesat disebabkan oleh sistem pengajian Pendidikan Islam di sekolah pondok yang hampir tidak menyeluruh. Tujuan utama sistem pendidikan pondok ialah melahirkan pelajar yang hanya menumpukan soal akhirat sematamata. Bukan itu sahaja, sistem pengajiannya yang hampir tidak menekankan matlamat untuk menyediakan belia untuk menghadapi perubahan sosio-ekonomi atau memainkan peranan yang lebih menyeluruh. Fenomena ini telah menyebabkan masyarakat Melayu Islam kelihatan mundur dalam pelbagai aspek kehidupan. Kemunculan sistem pengajian Madrasah adalah disebabkan oleh pengaruh dari Timur Tengah juga memainkan peranan penting dalam mencorakkan sistem Pendidikan Islam di Tanah Melayu.

Sekolah Inggeris pada awal abad ke-18 yang muncul memberi kesan yang besar terhadap masyarakat Islam di negara ini. Masyarakat Islam pada ketika itu bimbang terhadap pertumbuhan sekolah tersebut. Ibu bapa risau anak mereka akan terpengaruh dengan dakyah agama Kristian dan merupakan satu ancaman kepada pendidikan Islam. Kesan kebimbangan ini telah mempercepatkan lagi pengasasan dan penubuhan madrasah di Tanah Melayu. Di samping itu, pelajar Melayu yang belajar di Timur Tengah pada abad ke-20 telah terpengaruh dengan pemikiran Islah yang dipelopori oleh Syed Jamaluddin al-Afghani dan Muhammad Abduh yang telah membawa perubahan besar terhadap sistem pendidikan di al-Azhar dan pemikiran mereka ini telah menyebabkan Syed Syeikh al-Hadi dan rakannya mendirikan madrasah untuk memberi pendidikan kepada anak Melayu Islam dengan lebih komprehensif dan sistematik. 


\subsection{SOROTAN LITERATUR}

Sorotan literatur telah dilakukan ke atas beberapa kajian telah dihasilkan oleh beberapa penulis. Antaranya kajian yang dilakukan ke atas Latihan Ilmiah yang dihasilkan oleh Muhammad Daud yang bertajuk 'Madrasah Al-Mashoor Al-Islamiyah Pulau Pinang: 1916 - 1969'. Melalui latihan ilmiah ini dinyatakan mengenai sejarah perkembangan pengasasan Madrasah al-Mashoor pada tahun 1916 sebagai langkah untuk menyebarkan pendidikan agama Islam. Masyarakat Islam yang lain kemudiannya bersama-sama turut serta berusaha memberikan sumbangan bakti yang sungguh berharga dari segi material dan moral demi menjaga keutuhan Madrasah al-Mashoor.

Kajian ini juga meneliti mengenai zaman keagungan kerana beberapa faktor yang sungguh menarik. Seterusnya, penulis juga menyatakan Madrasah al-Mashoor telah berkembang pesat menjadi sebuah institusi Pendidikan Islam di Pulau Pinang dan dapat memberi pendidikan Islam kepada masyarakat dengan lebih sempurna. Walaupun begitu, kelemahan kajian ini dapat dilihat apabila penulis hanya menulis tidak secara deskriptif mengenai pengaruh Timur Tengah yang memainkan peranan penting dalam membangunkan serta memajukan madrasah.

Bagi mengkaji tentang Madrasah al-Mashoor ini, terdapat satu artikel dalam Jurnal Penyelidikan Sejarah Islam Pulau Pinang yang bertajuk 'Madrasah al-Mashoor al-Islamiah, Pulau Pinang: Pengaruh dan Perkembangan' yang telah ditulis oleh Amini Amir Abdullah pada tahun 1997. Dalam artikel ini, penulis ini hanya menulis mengenai pengaruh yang terdapat pada setiap mudir Madrasah alMashoor untuk menggambarkan perkembangan madrasah ini tetapi ruang lingkup yang agak ringkas. Namun pada pendapat penulis, kebanyakan kajian-kajian awal tentang perkembangan pendidikan di Tanah Melayu hampir tidak menyentuh mengenai institusi pendidikan Islam.

Selain itu juga penulisan mengenai madrasah ini juga dapat dilihat melalui buku yang diterbitkan oleh Persatuan Sejarah Malaysia iaitu Islam Di Malaysia, Rahim Osman yang menulis mengenai 'Madrasah Masyhur al-Islamiyyah'. Berdasarkan bacaan yang dibuat oleh penulis, ia menceritakan tentang salah sebuah pusat pengajian agama yang terkemuka di Tanah Melayu sebelum perang, telah banyak memberi latihan, bukan hanya dalam bidang falsafah agama kepada ramai pemuda dan pemudi. Dalam penulisannya, beliau hanyalah semata-mata menceritakan perkembangan sejarah Madrasah al-Mashoor.

Dalam sub topik 'peranan dan sumbangan pengaruh Mesir' di dalam buku tulisan Mohammad Redzuan Othman iaitu Islam dan Masyarakat Melayu: Peranan dan Pengaruh Timur Tengah, Sejarah dan perkembangan Madrasah al-Mashoor al-Islamiah juga diceritakan agak ringkas kerana lebih menekankan kesedaran politik masyarakat Melayu pada 1920-an dan 1930-an disumbangkan oleh peranan yang dimainkan oleh pelajar yang menuntut di Kaherah Mesir. Iklim politik yang menggalakkan dan wujudnya kemudahan percetakan membolehkan pelajar-pelajar ini memainkan peranan menyebarkan kesedaran sosial dan politik kepada masyarakat Melayu melalui tulisan dalam akhbar yang mereka terbitkan.

Dalam buku Islamic Modernism in Malaya; The Life And Thought of Sayid Syeikh al-Hadi 1867-1934 hasil tulisan Ibrahim Abu Bakar, perkara berkaitan Madrasah hanya sedikit sahaja yang disentuhnya dan hanya menceritakan sejarah perkembangan secara ringkas tentang penubuhan madrasah di Tanah Melayu bermula dengan Madrasah Masriyah Bukit Mertajam pada 1906 dan merupakan perubahan penting daripada sistem pendidikan pondok kepada sistem persekolahan yang lebih teratur.

Begitu juga dengan buku yang bertajuk Pengenalan Tamadun Islam di Malaysia hasil tulisan Abdullah Jusuh dalam sub topik pendidikan juga menceritakan secara ringkas mengenai sistem madrasah yang terdapat di Malaysia. Melalui buku ini, penulis hanya menghuraikan konsep dan matlamat pendidikan Islam sebagai teras pembangunan diri, masyarakat dan tamadun umat, institusi pendidikan informal, sistem pengajian pondok dan sistem madrasah sehingga berkembang menjadi institusi pendidikan formal di peringkat menengah dan pengajian tinggi.

\subsection{METODOLOGI KAJIAN}

Kajian ini menggunakan kaedah kualitatif iaitu yang melibatkan pengumpulan dan menganalisis data. Terdapat dua kaedah kajian yang telah dipilih dalam penyelidikan ini. Kaedah pertama yang digunakan ialah melakukan kajian ke atas dokumen dan fail di Arkib Negara. Kajian ini dilakukan dengan mendapatkan sumber primer untuk dijadikan bahan bukti dalam penulisan ini. Data sumber primer yang digunakan ialah karya hasil peninggalan tokoh seperti surat persendirian, jurnal terbitan madrasah dan koleksi simpanan individu untuk memperoleh data yang diperlukan.

Kaedah yang kedua untuk mendapatkan maklumat yang akan digunakan dalam kajian ini ialah kajian perpustakaan. Kajian perpustakaan dilakukan dengan mendapatkan buku dan bahan bertulis lain seperti akhbar, jurnal, artikel dan majalah. Melalui kaedah ini dapat memudahkan penyelidik untuk memahami serba sedikit latar belakang mengenai Madrasah al-Mashoor al-Islamiah. Pada yang sama juga penyelidik turut meneliti beberapa kajian lepas yang telah dilakukan ke atas beberapa sumber sejarah tempatan. Sumber-sumber ini boleh didapati di Perpustakaan Negara, Perpustakaan Universiti Malaya, Perpustakaan Tun Sri Lanang Universiti Kebangsaan Malaysia, Perpustakaan Universiti Putra Malaysia, Pusat Islam dan Perpustakaan Hamzah Sendut Universiti Sains Malaysia.

\subsection{PENGANALISAAN \& DAPATAN KAJIAN}

Sejarah Awal Madrasah al-Mashoor al-Islamiah

Sebelum tahun 1914, masyarakat Islam yang berketurunan Arab di sekitar Lebuh Acheh memikirkan mengenai pendidikan Islam dalam kalangan anak mereka dan timbul idea untuk mengasaskan sebuah sekolah agama yang dinamakan Madrasah al-Quran. Idea ini timbul pada 16 Muharam 1335H atau pada 11 November 1916 (Md. Khair, 1987) setelah mereka merasa sedar mengenai keperluan anak-anak mereka kepada didikan agama yang menyeluruh. Mereka telah bermesyuarat dan bertukar-tukar pendapat bagi mencari jalan bagaimana untuk menyelamatkan anak-anak orang Islam daripada menjadi mangsa kejahilan.

Madrasah ini kemudiannya berkembang pesat dan berpindah ke Kampung Jawa Lama dengan nama barunya, Madrasah alMashoor al-Islamiah yang kemudiannya berpindah sekali lagi ke Lebuh Tek Soon. Idea ini timbul setelah mereka merasa sedar mengenai 
keperluan anak-anak mereka kepada didikan agama yang menyeluruh. Perkembangan dan pengaruh madrasah ini bukan hanya di sekitar Tanah Melayu sahaja tetapi menjangkau ke seluruh Asia Tenggara dan Timur Tengah. William R. Roff menganggap Madrasah al-Mashoor al-Islamiah ini sebagai sebuah sekolah agama yang terkenal di Tanah Melayu (Roff, 1967).

Ahli Jawatankuasa yang telah menjayakan rancangan 'Madrasatul al-Quran' itu ialah Syed Mahdhar Aidid, Syed Syeikh Ali Bawazir, Syed Omar al-Sagoff, Syed Amar Mahdhar dan Syed Hassan al-Baghdad dan Syeikh Haji Zakaria. Mereka ini terdiri daripada orang Arab yang dianggap sebagai pemimpin masyarakat Islam yang terkenal pada masa itu. Ahli Jawatankuasa tersebut diketuai oleh Syed Abdul Rahman al-Habsyi. Sumber kewangan untuk menjayakan madrasah itu akan dikutip daripada derma saudagar Arab dan penduduk Islam di sekitar Pulau Pinang. Madrasah yang baru dibuka itu mendapat sambutan yang baik daripada masyarakat Islam di Pulau Pinang. Pihak ahli jawatankuasa juga telah melantik Syed Abdul Rahman menjadi guru yang pertama di madrasah dan beliau sendiri mengajar al-Quran. Madrasah ini mempunyai kumpulan murid yang pertama seramai 16 orang anak lelaki yang kebanyakannya adalah anak orang Arab. (Muhammad Daud, 1980)

\section{Peranan Syed Syeikh al-Hadi}

Selepas beberapa tahun Madrasah al-Quran beroperasi, Syed Syeikh al-Hadi telah dilantik sebagai mudir pertama di Madrasah al-Mashoor al-Islamiah. Nama madrasah ini telah ditukar sempena nama seorang penghulu yang terkenal di Pulau Pinang. (Muhammad Sarim, 1975) Al-Hadi merupakan seorang peguam telah membawa perubahan yang besar kepada madrasah ini sesuai dengan idea islahnya yang diperolehi daripada Timur Tengah. Di Timur Tengah ketika itu sedang bertiup kencang angin perubahan terutamanya dalam soal pendidikan yang ditiupkan oleh Sayyid Jamaluddin al-Afghani dan Muhammad Abduh serta Rashid Rida. Al-Hadi dilahirkan pada petang Selasa, 25 Rejab tahun 1281 Hijrah bersamaan tahun 1867 Masihi di Kampung Hulu, Melaka (Zainon Ahmad, 1979). Pada tahun kelahirannya, mempunyai erti yang besar kepada sejarah Tanah Melayu ketika itu dengan berlakunya perpindahan pentadbiran pejabat Negeri-negeri Selat dari Pejabat Tanah Jajahan di London ke Singapura. Peristiwa ini banyak mempengaruhi sejarah Tanah Melayu dan kehidupan al-Hadi sebagai pengarang dan reformis Islam kemudiannya (Talib Samat, 1996).

Pengaruh pemikiran Abduh telah diperkembangkan oleh al-Hadi dan pemergian beliau ke Timur Tengah, khususnya Mesir bersama keluarga Diraja Riau telah memberi kesempatan kepadanya untuk melihat kemajuan bangsa lain dari segi pemikiran dan kebudayaan. Beliau bukan sahaja berpeluang melawat Mesir dan negeri lain di Timur Tengah tetapi berkesempatan bertemu dengan Abduh dan Rida. (Linda Tan, 1999) Pengetahuan serta fahaman pembaharuan Islam yang dipelopori oleh Abduh itu diterapkan kepada masyarakat Melayu (Nurizan, 2011). Kunjungan ini bertujuan untuk melawat dan menggunakan kesempatan yang ada itu untuk mendalami ilmu pengetahuannya dalam bahasa Arab dan agama Islam. Di Kaherah, al-Hadi terdedah kepada perkembangan yang berlaku di Timur Tengah, mempunyai hubungan dengan Mesir dan terpengaruh dengan pemikiran akhbar al-Manar (Mohammad Redzuan, 2012). Melalui peranan yang dimainkan oleh Abduh dan Rida yang terkenal dengan pemikiran yang progresif telah berjaya membawa pembaharuan dalam cara berfikir dan pembangunan masyarakat di Timur Tengah. Sejarah membuktikan al-Hadi mempunyai semangat dan fikiran yang progresif dan cuba membawa pembaharuan dalam masyarakat Melayu, terutama dari segi pandangan masyarakat Melayu terhadap agama Islam.

\section{Sistem Pengajian Madrasah}

Sistem pengajian madrasah yang dipelopori al-Hadi ini merupakan pengaruh dari Timur Tengah dan telah memberi kesan yang tidak sedikit kepada pengajian pondok yang telah lama bertapak di Negeri-negeri Melayu khususnya di Pantai Timur. Sistem pengajian ini memberi saingan juga kepada sistem pendidikan sekular yang dianjurkan oleh penjajah Inggeris. Sistem ini juga bertujuan melahirkan pelajar yang alim, berilmu dan bertanggungjawab kepada dirinya, bangsa dan agama (Talib Samat, 1996).

Sebagaimana pandangan Abduh, al-Hadi percaya bahawa tahap ilmu dan pendidikan yang rendah dalam kalangan orang Islam merupakan faktor penghalang kemajuan dalam hidup. Berdasarkan pengamatan terhadap sosiopolitik orang Melayu, beliau berkeyakinan bahawa mereka mampu mencapai kemajuan sekiranya mendapat pendidikan yang mencukupi dan memiliki ilmu yang sesuai dengan peredaran masa. Atas keyakinan bahawa ilmu dan pendidikan adalah alat untuk membawa perubahan minda dan sikap, beliau telah mendirikan beberapa institusi pendidikan moden di beberapa negeri di Tanah Melayu dengan mengekalkan konsep agama.

Hasil pengaruh pemikiran Abduh telah mendorong al-Hadi menerapkan ilmu agama yang diperolehnya menerusi sistem pengajian di Madrasah al-Iqbal al-Islamiyah, Madrasah al-Hadi di Melaka dan Madrasah al-Mashoor al-Islamiah di Pulau Pinang serta di dalam majalah al-Imam. Beliau sentiasa menekankan betapa umat Islam perlu membebaskan diri mereka daripada belenggu khurafat dan memberikan tanggapan yang wajar berdasarkan akal fikiran terhadap ajaran Islam yang sebenar. Pertemuan yang berlaku di antara al-Hadi dan Abduh telah mempengaruhi pemikiran beliau dengan memberi tumpuan dan penekanan kepada pendidikan. Walau bagaimanapun, terdapat sedikit perbezaan berkenaan pembaharuan institusi yang dipelopori oleh kedua-dua tokoh ini di mana Abduh telah melakukan pembaharuannya ke atas institusi pengajian atau peringkat tinggi manakala al-Hadi menumpukan pembaharuannya bermula dari peringkat rendah lagi (Saifullah, 2007).

Kerjasama antara lulusan dari Timur Tengah dilihat sekali lagi sama-sama berusaha untuk merubah sistem pendidikan bangsa Melayu di Tanah Melayu. Penggemblengan tenaga dilaksanakan bagi mewujudkan sistem pendidikan Islam yang lebih segar, moden dan sistematik sesuai dengan peredaran zaman dan masa. Apa yang ditekankan di sini ialah sistem pondok yang bercorak Fatani yang diusahakan oleh lulusan Makkah dianjurkan untuk mempertingkatkan lagi sistem pelajarannya. Selain itu, lulusan al-Azhar telah membina sistem pendidikan Islam dalam bentuk sekolah yang lebih tersusun dan sistematik dengan menekankan subjek-subjek moden seperti bahasa Melayu, Matematik, Sains dan Sejarah dan diimbangi dengan subjek agama, akhlak dan bahasa Arab (Abdul Halim, 1984).

Sistem pondok yang sedia ada tidak terus hilang begitu sahaja dengan kewujudan sistem pendidikan Islam secara madrasah tetapi terus berjalan seiringan untuk beberapa tempoh sehinggalah para penuntut sistem pondok sendiri merasai kekurangan daripada sudut ilmu berbanding penuntut yang mendapat pendidikan Islam secara sistematik yang lebih tersusun. Keadaan ini mempercepatkan lagi proses perkembangan pendidikan Islam di Tanah Melayu dan memangkinkan sistem pondok bertukar wajah. Sistem pondok tetap terus berjalan namun dengan suntikan subjek moden dan bersesuaian dengan peredaran masa. Subjek yang diajar adalah seimbang dengan tuntutan duniawi dan ukhrawi. Hal ini diadaptasi daripada sistem sekolah Pendidikan Islam yang menerima pengaruh daripada Timur Tengah. 


\section{Sistem kurikulum}

Pengaruh Timur Tengah juga dapat dilihat dalam sistem kurikulum madrasah tersebut. Pada zaman al-Hadi menjadi mudir, beliau sendiri mengajar subjek Bahasa Arab, Kesusasteraan Arab, Fiqah dan Balaghah (Mahyudin, 1999). Selain itu, beliau telah memperkenalkan sistem peperiksaan tahunan, mengadakan majlis syarahan dan perbahasan dalam kalangan para pelajar. Pertandingan syarahan, membaca al-Quran, perbahasan dan lakonan diadakan pada setiap hujung minggu. Tujuan program ini adalah untuk melatih serta membuka fikiran para pelajarnya dan memberi peluang kepada mereka bertukar-tukar pendapat. Pelbagai perubahan baru diperkenalkan di madrasah tersebut baik dari segi sukatan pelajarannya mahupun kepada struktur pentadbirannya.

Pada zaman Syeikh Abdullah al-Maghribi pula, beliau telah menekankan subjek agama Islam, bahasa Arab dan bahasa Inggeris di madrasah ini. Terdapat subjek baru yang diperkenalkan adalah seperti Tafsir, Fiqah, Hadis, Mantik, Insha, Balagha dan Nusus. Kesemua subjek ini tidak pernah diajar semasa al-Hadi menjadi mudir. Selain itu, al-Maghribi telah menjadikan bahasa Arab sebagai bahasa pengantar di madrasah ini dan buku muktabar ulama Islam yang berbahasa Arab telah dijadikan sebagai buku teksnya. Subjek yang diajar di madrasah ini adalah seperti Ilm al-Fiqh, Usul al-Fiqh, Nahu, Saraf, Balaghah, al-Adab al-Arabiyyah, Ilm al-Mantiq, Falsafah, Aqidah, Tafsir, Ulum al-Quran, Ilm al-Hadith, bahasa Arab dan Sejarah Perkembangan Mazhab. Kitab-kitab terkenal yang diajar di madrasah ini ialah seperti kitab Subul al-Salam, Nail al-Awtar, dan al-Umm. Sistem pendidikan dan kurikulum Madrasah al-Mashoor terdiri daripada kelas bahasa Arab yang diadakan pada waktu pagi iaitu dari pukul 8.00 pagi sehingga 12.00 tengahari. Bahagian Arab mempunyai tiga peringkat kelas iaitu: Tahdiri, Ibtidai dan Thanawi. Kelas Tahdiri adalah peringkat paling rendah dan tempoh pengajiannya di antara satu hingga dua tahun. Pelajar baru yang tiada asas agama Islam dan bahasa Arab mesti memasuki kelas Tahdiri ini terlebih dahulu sebelum boleh ke kelas Ibtidai. (Muhammad Daud, 1980).

Pihak madrasah akan mengadakan ujian lisan kepada pelajar baru yang hendak melanjutkan pelajaran di madrasah ini. Selepas ujian lisan diadakan dan keputusan telah diumumkan, pelajar tersebut akan ditempatkan di kelas yang sesuai dengan kebolehannya. Pelajar yang sudah mempunyai asas bahasa Arab dan agama Islam yang tertentu akan dimasukkan ke kelas Ibtidai atau Thanawi. Biasanya pelajar yang pernah belajar di madrasah yang lain sebelum memasuki Madrasah al-Mashoor akan ditempatkan di peringkat Ibtidai atau Thanawi itu. Kelas Tahdiri ini telah wujud dari pengasasan madrasah pada tahun 1916. Subjek yang diajar di dalam kelas Tahdiri ialah membaca alQuran, Nahu, Khat dan Rencana Arab. Pelajar terpaksa menduduki peperiksaan tahunan sebelum boleh dinaikkan ke kelas Ibtidai. Pelajar yang tidak lulus peperiksaan akan menunggu di kelas Tahdiri sehingga mereka lulus.

Kelas Ibtidai adalah peringkat pengajian rendah di Madrasah al-Mashoor. Kelas ini telah wujud sejak tahun 1916 dan terdapat empat kelas iaitu Ibtidai Satu, Ibtidai Dua, Ibtidai Tiga dan Ibtidai Empat. Pelajar haruslah lulus terlebih dahulu dalam Ibtidai Satu sebelum boleh naik ke Ibtidai Dua dan begitulah proses seterusnya. Subjek yang diajar pada peringkat Ibtidai ini adalah seperti Mutalaah, Nahu, Saraf, Mahfuzat, Bacaan, Khat, Karangan dan Rencana. Pelajar yang telah lulus peperiksaan di peringkat akan dianugerahkan Shahadah Ibtidaiyah. Selain itu, peringkat Thanawi pula atau peringkat menengah telah bermula sejak tahun 1920 dan terdapat empat darjah Thanawi di madrasah ini iaitu Thanawi Satu, Thanawi Dua, Thanawi Tiga dan Thanawi Empat. Subjek yang diajar pada peringkat ini ialah Fiqah, Tauhid, Tafsir, Hadis, Sejarah Islam, Usul Fiqh dan Faraid. Pelajar-pelajar yang lulus peperiksaan di peringkat Thanawi ini akan dianugerahkan sijil Shahadah Thanawiyah. (Muhammad Daud, 1980).

Kualiti pengajian bahasa Arab di Madrasah al-Mashoor adalah tinggi kerana disebabkan oleh guru yang mengajar subjek ini adalah terdiri daripada orang Arab. Kebanyakan bekas pelajar madrasah ini yang melanjutkan pelajaran ke Timur Tengah tidak menghadapi masalah bahasa Arab kerana telah mendapat pendedahan awal. Pengajaran Bahasa Arab di madrasah ini juga amat mementingkan aktiviti praktikal seperti bertutur dan menulis daripada Nahu bahasa Arab. Oleh itu, kebanyakan bekas pelajar madrasah boleh bertutur dan menulis Bahasa Arab dengan baik walaupun kurang memahami struktur Nahu bahasa Arab. Ramai pelajar dari madrasah lain di Semenanjung Tanah Melayu melanjutkan pelajaran ke Madrasah al-Mashoor adalah semata-mata untuk meningkatkan lagi pengetahuan bahasa Arab mereka. Madrasah al-Mashoor bukan sahaja terkenal di Tanah Melayu malah dikenali sehingga di Indonesia dan Thailand. (Muhammad Sarim, 1975).

\section{Tenaga pengajar}

Madrasah al-Mashoor juga memiliki tenaga pengajar yang kebanyakannya berasal dari Timur Tengah. Tenaga pengajar madrasah ini terdiri daripada kenalan dan sahabat mudir madrasah yang telah menjemput mereka untuk mengajar di madrasah ini. Al-Hadi juga telah menulis surat kepada seorang temannya di Makkah bernama Syed Tahsin Alkaff untuk mencari seorang guru yang berasal dari Timur Tengah untuk bertugas di madrasah ini. Syed Tahsin Alkaff dengan pertolongan kawannya, Syeikh Ahmad al-Najar berjaya menghubungi al-Maghribi (Muhammad Sarim, 1976). Al-Maghribi adalah seorang guru yang berpengalaman dan beliau adalah seorang ulama yang pernah mengajar di Masjid al-Haram, Makkah. Beliau menamatkan pengajian agamanya dengan mencapai ijazah Shahadah 'Alamiyyah. Beliau bertugas sebagai guru bersama-sama dengan al-Hadi. Bukan itu sahaja, Syeikh Tahir Jalaluddin juga turut menjadi tenaga pengajar di madrasah ini di dalam bidang ilmu Falak. Al-Hadi telah berusaha untuk meningkatkan mutu pembelajaran dan pengajaran di madrasah ini dan antara guru yang membantu beliau di dalam pengajaran ketika itu adalah seperti Syeikh Muhammad Radzi, Syed Ahmad Dahlan, Abdul Rahman Firdaus, Syed Ali al-Zahir dan Ustaz Yusof Zawawi.

Selepas al-Hadi meletakkan jawatan sebagai mudir, al-Maghribi telah dilantik sebagai mudir Madrasah al-Mashoor yang baru dan menyandang jawatan ini hingga ke tahun 1921. Beberapa orang guru dari Mesir dan Makkah telah dijemput oleh al-Maghribi untuk mengajar di madrasah ini. Al-Maghribi terkenal sebagai ulama yang liberal, membawa idea islah dan pembaharuan di dalam aliran pemikiran pelajar dan masyarakat Islam seluruhnya. Pengalamannya semasa di Makkah besar kemungkinan mempengaruhi pemikirannya. Di Makkah ketika itu sedang tersebar idea Muhammad bin Abdul Wahab. Aliran pemikiran itu dipercayai cuba diterapkan di Madrasah alMashoor al-Islamiah. Beberapa perubahan drastik cuba diperkenalkan yang bertentangan dengan fahaman Kaum Tua. Tidak hairanlah jika beliau dikecam sebagai golongan Kaum Muda (Roff, 1974). Faktor lain yang membantunya menyebarkan idea islah ialah hasil perkenalannya dengan Tahir Jalaluddin dan inspirasi daripada al-Hadi sendiri (Ermy \& Salasiah, 2008).

Beberapa orang guru dari Mesir dan Makkah dijemput oleh al-Maghribi untuk mengajar di Madrasah al-Mashoor. Syeikh Ahmad al-Hadi dan Hapiz Ghulam Sarwar merupakan di antara guru yang mengajar semasa pentadbiran al-Maghribi. Beliau menduduki jawatan mudir Madrasah al-Mashoor selama kira-kira dua tahun setengah setelah meletakkan jawatannya. 
Satu kejayaan yang menempa sejarah kepada Madrasah al-Mashoor semasa al-Maghribi menjadi Mudir ialah di mana buat pertama kalinya beberapa orang pelajar madrasah ini diterima belajar di universiti al-Azhar, Mesir, Makkah dan di Iraq dalam pelbagai bidang ilmu agama. Kejayaan ini tidak dapat dinafikan lagi kerana kebolehan pelajar dalam menguasai bahasa Arab. Semasa al-Hadi menjadi Mudir di Madrasah al-Mashoor, beliau telah berusaha untuk menghantar pelajar Madrasah al-Mashoor melanjutkan pelajaran ke universiti di Timur Tengah tetapi masih belum berjaya. Tidak lama selepas itu, beliau terpaksa meletakkan jawatan sebagai mudir dan ahli jawatankuasa madrasah kerana masalah kesihatan dan berniat untuk pulang sahaja ke Makkah.

Sebelum meninggalkan Madrasah al-Mashoor, al-Maghribi berusaha mencari seorang mudir sebagai pengganti beliau. Pada masa itu, seorang Arab yang datang dari Pontianak, Kalimantan sempat singgah sebentar di Madrasah al-Mashoor sebelum meneruskan perjalanannya ke Makkah. Beliau adalah Syed Ali Abdullah al-Zawawi, seorang Mufti di Makkah. Al-Maghribi meminta Syed Ali mencari seorang guru atau calon yang layak untuk menjadi mudir Madrasah al-Mashoor apabila beliau kembali ke Makkah nanti. Semasa singgah di India, Syed Ali berjumpa dengan dua orang Arab bernama Syeikh Ibrahim Biyari dan Syeikh Abbas Bakar Rafiee. Syed Ali menyampaikan hasrat al-Maghribi kepada Syeikh Ibrahim dan Syeikh Abbas bahawa Madrasah al-Mashoor al-Islamiah di Pulau Pinang sedang mencari seorang guru untuk memegang jawatan mudir Madrasah al-Mashoor al-Islamiah. Mereka berdua sanggup datang ke Pulau Pinang dengan syarat pihak madrasah dapat menanggung bayaran tambang perjalanan mereka dari India ke Pulau Pinang. Semasa berada di Makkah, Syed Ali menghubungi al-Maghribi di Pulau Pinang melalui telegram dan menyatakan segala syarat yang dikehendaki oleh Syeikh Ibrahim dan Syeikh Abbas Bakar Rafiee (Omar Farouk, 1978).

Al-Maghribi telah memaklumkan kepada ahli jawatankuasa Madrasah al-Mashoor berita yang diterima olehnya itu. Pihak ahli jawatankuasa menerima segala syarat itu dan sanggup menanggung tambang perjalanan Syeikh Ibrahim dan Syeikh Abbas dari Bombay, India ke Pulau Pinang. Al-Maghribi telah melatih dua orang guru baru itu untuk mengajar di Madrasah al-Mashoor sebelum beliau meletak jawatan. Selepas peletakan jawatan al-Maghribi, Ahli jawatankuasa Madrasah al-Mashoor telah bersetuju untuk menerima Syeikh Abbas dan Syeikh Ibrahim Biyari untuk menjadi guru di madrasah ini. Beliau juga telah dilantik dengan rasmi menjadi mudir madrasah ini pada tahun 1922 dengan menggantikan Hapiz Ghulam Sharwar yang telah memangku jawatan mudir buat sementara waktu selepas peletakan jawatan al-Maghribi dan Syeikh Ibrahim Biyari pula telah dilantik sebagai Penolong Mudir. Pada peringkat awal pentadbiran Abbas Rafiee, terdapat tiga orang guru pelatih sebagai pembantunya (Muhammad Daud, 1980). Syeikh Abbas telah memperkenalkan beberapa pembaharuan di dalam kurikulum pembelajaran dan struktur pentadbiran Madrasah al-Mashoor al-Islamiah.

Buat pertama kalinya juga, Syeikh Abbas telah menghantar beberapa pelajar lepasan Madrasah al-Mashoor ke Universiti alAzhar, Mesir untuk melanjutkan pelajaran di peringkat sarjana muda. Bantuan kewangan diperolehi melalui derma para hartawan Arab dan India Muslim di Pulau Pinang ketika itu atas permintaan al-Maghribi sendiri. Beliau telah memperkenalkan beberapa pembaharuan dalam struktur pentadbiran Madrasah al-Mashoor al-Islamiah. Ketika ini juga Madrasah al-Mashoor al-Islamiah juga telah mempunyai Jawatankuasa Jemaah Pentadbirnya sendiri. Tugas jawatankuasa ini ialah menyediakan skim tangga gaji kepada gurunya dan mengesyorkan kurikulum, subjek dan buku teks serta rujukan yang harus digunakan. Jemaah ini juga telah berusaha untuk mendapatkan pengiktirafan daripada universiti di Mesir, India, Iraq dan beberapa negara Timur Tengah yang lain.

Ahli Jawatankuasa madrasah juga telah memohon Syeikh Abbas berusaha untuk mencari beberapa orang lagi guru dari Makkah memandangkan kepada jumlah pelajar yang semakin bertambah. Pada tahun 1923, Syeikh Abbas telah menulis surat kepada seorang sahabatnya Syeikh Muhammad Syatar dan adiknya Syeikh Mohd Hussain Bakar Rafiee yang sedang berada di Makkah meminta mereka datang ke Pulau Pinang untuk menjadi tenaga pengajar di madrasah ini. Syeikh Hussain serta Syeikh Muhammad melakukan pertemuan dengan ahli jawatankuasa madrasah dan berbincang mengenai jawatan guru dan syarat lain yang dikenakan. Namun begitu, Syeikh Muhammad tidak dapat menerima jawatan guru yang ditawarkan kepadanya dengan alasan gaji yang ditawarkan tidak memuaskan iaitu sebanyak lima puluh ringgit sahaja sebulan. Beliau terus meninggalkan Pulau Pinang dan pergi ke Indonesia untuk mencari pekerjaan lain yang lebih sesuai di sana.

Madrasah ini juga telah melatih dan mengasuh beberapa guru di antaranya ialah seperti Syeikh Ibrahim al-Masri dan Abdul Aziz Utaiqi. Tenaga pengajar luar berketurunan Melayu, Arab-Melayu, Indonesia dan Patani turut menyumbang tenaga di dalam memajukan madrasah ini. Beberapa orang guru daripada Arab Saudi turut mencurah bakti di madrasah ini, antaranya ialah seperti Hussain Rafiee sendiri. Selain itu, Syeikh Ibrahim Biyari merupakan salah seorang tenaga pengajar di Madrasah al-Mashoor semasa Syeikh Abbas memegang jawatan mudir (Ahmad Dzulfahmi, 2013).

\section{Penerbitan Majalah}

Pengaruh Timur Tengah dalam bidang pendidikan Islam dapat dilihat dalam penerbitan majalah. Ini merupakan langkah utama dalam memberi kesedaran dan kefahaman serta menyebarkan maklumat dengan lebih meluas lagi. Minat al-Hadi dalam bidang penulisan menjadi nyata dengan penerbitan majalah al-Imam di Singapura sekembalinya dari Timur Tengah. Majalah ini diterbitkan pada 22 Julai 1906 dan pada mulanya majalah ini dicetak oleh Matbaah Melayu Tanjung Pagar dan kemudiannya oleh al-Imam Printing Company Limited. AlImam mengandungi 32 halaman yang dijual dengan harga 25 sen pada ketika itu. Tujuan penerbitan majalah ini terungkap dengan jelas dalam rencana pengarangnya yang ditulis oleh Syeikh Mohd. Salim al-Kalali iaitu "mengingatkan mana yang lalai dan menjagakan mana yang tidur dan menunjukkan yang sesat dan menyampaikan suara yang menyeru dengan kebajikan” (Roff, 1967).

Secara tepatnya kandungan dan intisari majalah al-Imam ini menitikberatkan isu dan masalah utama seperti memperjuangkan Islam berdasarkan al-Quran dan Hadis, memberi galakan kepada orang Melayu supaya melakukan ijtihad dan menjauhkan diri daripada taklid buta serta menyarankan sistem pendidikan baru, iaitu satu sistem yang berdasarkan pendidikan Islam yang sihat serta ditambah tentang pengetahuan Arab, Inggeris, Ilmu Hisab dan agama. Penerbitan al-Imam terhenti pada tahun 1908 kerana kesulitan kewangan walaupun majalah ini pada dasarnya telah dapat memikat hati pembaca-pembaca di Tanah Melayu dan Indonesia (Linda Tan, 1999).

Hasil pengaruh pemikiran Abduh telah mendorong al-Hadi menerapkan ilmu agama yang diperolehnya menerusi sistem pelajaran di Madrasah al-Iqbal al-Islamiyah, Madrasah al-Hadi di Melaka dan Madrasah al-Mashoor di Pulau Pinang serta di dalam majalah al-Imam. Beliau sentiasa menekankan betapa umat Islam perlu membebaskan diri mereka daripada belenggu khurafat dan memberikan tanggapan yang wajar berdasarkan akal fikiran terhadap ajaran Islam yang sebenar. Jelaslah di sini, pertemuan yang berlaku di antara al-Hadi dan Abduh telah mempengaruhi pemikiran beliau dengan memberi tumpuan dan penekanan kepada pendidikan. Walau bagaimanapun, terdapat sedikit perbezaan berkenaan pembaharuan institusi yang dipelopori oleh kedua-dua tokoh ini. Muhammad Abduh 
telah melakukan pembaharuannya ke atas institusi pengajian atau peringkat tinggi manakala Syed Syeikh al-Hadi menumpukan pembaharuannya bermula dari peringkat rendah lagi (Saifullah, 2007).

Al-Imam juga telah mencetuskan kebangkitan kesedaran masyarakat Melayu yang telah dirintis oleh al-Hadi dan rakannya yang kebanyakannya berdarah Minang dan Arab tetapi amat prihatin dengan nasib masyarakat Melayu. Mereka bertanggungjawab menyedarkan masyarakat Melayu dan memberi bimbingan serta sumbangan dengan menegaskan agar masyarakat Melayu tidak berterusan leka sehingga menyebabkan kemunduran diri, tanah air, agama dan bangsa. Sebagaimana yang telah dinyatakan, mereka telah terpengaruh dengan citacita pembaharuan Abduh dan al-Afghani yang cuba mengembalikan umat Muslim kepada realiti ajaran agama Islam dan sekaligus menyaingi Barat.

Usaha di Mesir itu disalurkan melalui penerbitan al-Urwat al-Wusthqa dan al-Manar yang menekankan aspek pendidikan. Ini kerana pendidikan mampu mencorakkan norma kemajuan sesebuah masyarakat, bangsa serta negara dan pendidikan juga merupakan dasar ke arah pencapaian objektif islah. Usaha gigih al-Hadi dan rakannya dapat dilihat daripada rencana dan artikel yang ditulis dalam al-Imam sebagai wadah penyebaran maklumat untuk memberi kesedaran kepada masyarakat Melayu. Al-Imam telah menekankan kepentingan pendidikan Islam yang lebih sistematik sejak awal penerbitannya bersesuaian dengan tujuannya sebagai pencetus kebangkitan masyarakat Melayu Islam. Al-Imam turut menekankan ilmu sejarah kerana ia merupakan kunci kesedaran dan kemajuan sesebuah bangsa. Sejarah juga membuktikan bahawa pendidikan adalah satu-satunya kaedah utama pembangunan dan kemajuan.

Al-Imam juga menceritakan kisah ketua dan pemimpin zaman silam serta bagaimana dan apakah kaedah pemerintahan mereka dalam mentadbir urus negara dan sekali gus mengembangkan ajaran Islam ke pelosok dunia. Ini bertujuan untuk menyedarkan pemimpin Melayu serta raja Melayu mengenai tanggungjawab mereka terhadap bangsa dan negara (Khadijah dan Nor Adina, 2005). Al-Imam menyedari bahawa nasihat, teguran dan tunjuk ajar melalui rencana dan artikelnya tidak memadai bagi dijadikan kaedah untuk menegakkan bangsa Melayu. Namun, sekurang-kurangnya dapat menyedarkan bangsa Melayu mengenai kedudukan mereka di tanah air sendiri.

Peranan yang dibawa oleh Syeikh Hussain serta galakan daripada abangnya Syeikh Abbas telah menyebabkan pelajar telah berjaya menerbitkan sebuah majalah yang dinamakan al-Rajaa. Majalah ini adalah sebuah majalah yang pertama wujud di Tanah Melayu yang menggunakan dua bahasa pengantar iaitu Bahasa Arab dan Melayu (Jawi). Majalah ini diterbitkan pada setiap akhir bulan Islam kecuali bulan Ramadhan. Setiap naskhah dijual dengan harga 35 sen. Jika diteliti dari segi isi majalah ini, majalah ini membicarakan mengenai soal agama, sastera, pendidikan, semangat kebangsaan, sukatan pelajaran, hari peperiksaan dan iklan kemasukan pelajar ke madrasah tersebut.

Kewujudan sebuah majalah di Madrasah al-Mashoor pada masa itu adalah disebabkan oleh beberapa faktor seperti keadaan politik dan kemasyarakatan Pulau Pinang yang mengizinkan kerana terdapatnya kemudahan-kemudahan untuk mendapatkan kertas dan lain-lain bahan percetakan serta tempat percetakan kerana di Pulau Pinang sudah banyak akhbar dan majalah yang dikeluarkan oleh orangorang Jawi Peranakan dan Arab. Kebanyakan masyarakat Pulau Pinang juga sendiri sudah tahu membaca dan menulis. Namun begitu, Majalah al-Rajaa terpaksa memberhentikan penerbitannya kira-kira dua tahun kemudiannya iaitu pada tahun 1926 kerana mengalami masalah kewangan madrasah yang tidak mencukupi untuk menampung kos operasinya dan masalah pertukaran pelajar sama ada melanjutkan pelajaran ke luar negeri atau berpindah ke tempat lain atau berhenti dari madrasah (Ahmad Dzulfahmi, 2013).

\subsection{PERBINCANGAN \& CADANGAN}

Pengaruh Timur Tengah dalam sistem pendidikan Islam Madrasah al-Mashoor al-Islamiah memang tidak dapat dinafikan telah berjaya melahirkan modal insan yang berjaya. Segala pengalaman dan pengaruh yang dimiliki oleh mudir madrasah ini telah membuka lembaran baru dalam sistem pendidikan Islam di Tanah Melayu yang mana sistem yang berasaskan sistem pondok sebelum ini hanyalah menekankan proses penghafalan semata-mata. Pengaruh ini yang telah dibawa oleh lulusan dari Timur Tengah ini juga telah menimbulkan kesedaran mengenai Islam dalam masyarakat Melayu Islam.

Kesan daripada kebangkitan dan perkembangan di Timur Tengah telah memperlihatkan beberapa pembaharuan telah dilakukan oleh mudir Madrasah al-Mashoor al-Islamiah untuk mentarbiahkan masyarakat Melayu Islam khususnya yang selama ini telah terpengaruh dengan idea Kaum Tua yang hanya menekankan soal akhirat dan ini telah menyebabkan masyarakat pada ketika itu agak mundur dari arus pemodenan. Dengan memperkenalkan pelbagai pembaharuan dalam sistem pengajian, kurikulum dan tenaga pengajar serta dalam aspek penerbitan majalah di Madrasah al-Mashoor al-Islamiah, ini telah memberi satu nafas baru kepada sistem Pendidikan Islam dalam usaha untuk memodenkan diri sendiri dan masyarakat Melayu Islam di Tanah Melayu dan di Pulau Pinang khususnya.

\section{Rujukan}

‘Catatan Ringkas Riwayat Madrasah Mashoor Al-Islamiyah’. (1958). Cenderamata, Madrasah Mashoor Al-Islamiyah kerana Pembukaan Asrama Madrasah Mashoor Al-Islamiyah, Pulau Pinang. 1-12.

A.H. Edrus (1961), Persuratan Melayu 3: Drama dan Perkembangan Bahasa Melayu. 237. Singapura. Qalam,

Abdul Rahman Abdullah (1977), Pemikiran Islam Masa Kini: Sejarah dan Aliran. Dewan Bahasa dan Pustaka, Kuala Lumpur. 291.

Abdul Rahman Al-Ahmadi (2000), Tamadun Islam di Malaysia, Dewan Bahasa dan Pustaka, Kuala Lumpur. 492.

Ahmad Adam (1983), Pertumbuhan Kesedaran Sosial Orang Melayu di Melaka pada Tahun-tahun 1920-an dan 1930-an dalam Dokumentasi Seminar Sejarah Melaka (ed. Asmad), Kerajaan Negeri Melaka, Melaka. 302-303.

Ahmad Dzulfahmi Muhamad (2013). Sejarah dan Perkembangan Madrasah Al-Mashoor Al-Islamiah Pulau Pinang, 1916 - 1969, Disertasi Sarjana Sastera, Jabatan Sejarah Universiti Malaya, Kuala Lumpur. 54-161.

Amini Amir Abdullah (1997), 'Madrasah Al-Mashoor Al-Islamiah, Pulau Pinang: Pengaruh Dan Perkembangan', Jurnal Penyelidikan Sejarah Islam Pulau Pinang, $3(3), 29-44$

Amir Tan, ‘Almarhum Dr. Burhanuddin, Nasionalis Yang Tak Mengenal Kalah’, dlm. Dewan Masyarakat, Ogos 1975, 4.

Dr. Burhanuddin al-Helmy (2000), 'Perjuangan Kita, 1946', dlm. Kamaruddin Jaffar, Dr. Burhanuddin Al-Helmy Pemikiran dan Perjuangan. IKDAS, Kuala Lumpur. $1412 \mathrm{H} / 2000,31-60$

Ensiklopedia Sejarah Dan Kebudayaan Melayu (1998). Dewan Bahasa dan Pustaka, Kuala Lumpur. 3, 1386-1387. 
Ermy Azziati dan Salasiah Hanin Hamjah (2008), 'Syeikh Abdullah al-Ghadamishi al-Maghribi: Sumbangannya dalam Bidang Pendidikan dan Gerakan Islah', dlm. Nadwah Ilmiah al-Saniah Haul Syeikh Abdullah al-Ghadamisi (Maghribi) Dauruhu fi al-Dakwah wa I' Lam fi Biladi Malaya, Jabatan Dakwah dan Kepimpinan, Fakulti Pengajian Islam Universiti Kebangsaan Malaysia. 3.

Fuziah Shaffie dan Ruslan Zainuddin. (2000). Sejarah Malaysia. Penerbit Fajar Bakti Sdn. Bhd., Shah Alam. 338.

Ibrahim Abu Bakar. (1994). Islamic Modernism in Malaya: The Life and Thought of Sayid Syekh Al-Hadi 1867-1934. University of Malaya Press, Kuala Lumpur. 76.

Khadijah Mohd Khambali @ Hambali \& Nor Adina Abdul Kadir (2005), "Pengaruh Al-Azhar Terhadap Sistem Pendidikan Islam di Tanah Melayu-Malaysia. Jurnal Usuluddin, 22, 27-53.

Li Chuan Siu (1972), Ikhtisar Sejarah Kesusasteraan Melayu Baru 1930-1945, Penerbit Pustaka Antara, Kuala Lumpur. 30-36.

Linda Tan (1999), 'Syed Shaykh: His Life and Times', dalam Alijah Gordon (editor), The Real Cry of Syed Shaykh al-Hady. Malaysian Sociological Research Institute, Kuala Lumpur. 110.

Mahayudin Yahaya (1999), 'Abu Jabir Abd Allah b. Ahmad al-Ghadamisi: A Reformist Ulama In The Malay States', dalam Alijah Gordon (editor), The Real Cry of Syed Shaykh al-Hady, Malaysian Sociological Research Institute, Kuala Lumpur.239-242.

Majalah Putra SMKA Al-Mashoor(L)(2008). Percetakan Fadhilat, Pulau Pinang. 11-13.

Md. Khair Md Taib (1987), Takwim Hijriah Khairiah, Penerbit Universiti Kebangsaan Malaysia, Bangi. 100-102.

Mohammad Redzuan Othman (2005), Islam dan Masyarakat Melayu Peranan dan Pengaruh Timur Tengah. Penerbit Universiti Malaya, Kuala Lumpur. 109-130.

Mohd. Salleh Lebar (1988), Perubahan dan Kemajuan Pendidikan di Malaysia. Nurin Enterprise, Kuala Lumpur.20.

Muhammad Daud (1980), ‘Madrasah al-Mashoor al-Islamiah, Pulau Pinang: 1916-1969', Latihan Ilmiah, Universiti Kebangsaan Malaysia, Bangi, Selangor, 44-128.

Muhammad Sarim Mustajab (1975), ‘Islam dan Perkembangan Dalam Masyarakat Melayu di Semenanjung Tanah Melayu 1900-1940’, Tesis M.A, Jabatan Sejarah, Universiti Kebangsaan Malaysia, Bangi, $15-35$.

Muhammad Sarim Mustajab (1976), 'Syed Syeikh Abdullah Maghribi: Pendidik dan Kaum Muda', dalam Mohd. Yusof Ibrahim: Jebat, Bil5/6, Jabatan Sejarah, Universiti Kebangsaan Malaysia, Bangi, 1.

N. John Funston. (1980). Malay Politics in Malaysia, Study of UMNO and PAS. Heinemann Educational Books (Asia) Ltd., Kuala Lumpur. 118.

Nurizan Baharum (2011), 'Pengaruh Reformasi Pendidikan Muhammad Abduh', Prosiding Nadwah Ulama Nusantara (NUN) IV: Ulama Pemacu Transformasi Negara, 25-26 November 2011, 392-397.

Omar Farouk Shaeik Ahmad (1978), 'The Arabs in Penang', Malaysia in History, Special Issue Focus on Penang. XXI, 1-16.

Rahim Osman, (1980). 'Madrasah Masyhur Al-Islamiyyah', dalam Khoo Kay Kim, Islam Di Malaysia. Penerbit Persatuan Sejarah Malaysia, Kuala Lumpur. 76.

Rashidah Ismail (1969), 'Dr. Burhanuddin al-Helmy: Anak Melayu Yang Pertama Mempelajari Homeopati'. Dewan Masyarakat, 23.

Rustam A. Sani (1975), 'The Origin of the Malay Left: An Analysis of the Social Root'. Tesis M.A., University of Kent, Canterburry, 41-42.

S.H. Tan (1961), 'The Life and Times of Sayyid Shaykh Ahmad al-Had'I', Latihan Ilmiah B.A. Universiti Malaya, Singapore, 1.

Saifullah Mohd Sawi (2007), Sejarah dan Tamadun Islam di Asia Tenggara. Karisma Publications, Shah Alam, Selangor. 83.

Saliha Hassan (1997), 'Dr. Burhanuddin al-Helmi 1911-1969', dlm. Abdullah Zakaria dan Adnan Nawang, Biografi Tokoh Pilihan Malaysia. Penerbit Universiti Malaya, Kuala Lumpur.1.

SP10/583, 'Undang-undang Penubuhan Lembaga Pengelola Madrasah al-Mashoor Pulau Pinang', Surat Persendirian Syeikh Tahir.

SP63/4, 'Penubuhan Sekolah-Sekolah Agama', Surat Persendirian Fathil Basheer, 1-3.

SPP/P/1, 'Sejarah Madrasah al-Mashoor al-Islamiah (Lelaki dan Perempuan) Pulau Pinang', Surat Persendirian Shaikh Ahmad Osman Bajunid, 2-16.

Talib Samat (1996), 'Syed Syeikh Al-Hadi: Pelopor Pendidikan Islam Terawal di Pulau Pinang', Sejarah Islam Pulau Pinang, Tokoh dan Sumbangan, 2,(2), $20-41$.

Talib Samat (2007), 'Madrasah al-Mashoor al-Islamiah: Sekolah Agama Pertama di Pulau Pinang', dalam Sohaimi Abdul Aziz, Dari Tanjung Penaga ke Georgetown:Membongkar Sejarah Negeri Pulau Pinang, Pulau Pinang: Kementerian Kebudayaan, Kesenian dan Warisan Malaysia, 139.

William R. Roff (1967), The Origins of Malay Nationalism, Kuala Lumpur: University of Malaya Press, 82.

Yahaya Ismail (1974), 'Syed Syeikh Ahmad Al-Hadi: Pembuka Zaman Baru dalam Bidang Novel di Bumi Pulau Pinang', dalam Dewan Bahasa, 551. 